RUNNING HEAD: Mental rotation and Williams syndrome

Mental rotation in Williams syndrome: an impaired ability

\author{
Chris Stinton
}

Institute of Psychiatry, King's College London, UK

Emily K. Farran

School of Psychology and Clinical Language Sciences, University of Reading, UK

Yannick Courbois

UFR de Psychologie, Université de Gaulle, Lille, France 


\begin{abstract}
Typically developing young children and individuals with intellectual disabilities often perform poorly on mental rotation tasks when the stimulus they are rotating lacks a salient component. However, performance can be improved when salience is increased. The present study investigated the effect of salience on mental rotation performance by individuals with Williams syndrome. Individuals with Williams syndrome and matched controls were presented with two versions of a mental rotation task: a no salient component condition and a salient component condition. The results showed that component salience did not benefit individuals with Williams syndrome in the same manner as it did controls.
\end{abstract}

Key words: Williams syndrome, mental rotation, stimulus salience 


\section{Mental rotation in Williams syndrome: an impaired ability}

\section{Introduction}

\section{Characterisation of Williams syndrome}

Williams syndrome (WS) is a rare genetic disorder that arises from a microgenetic deletion on the long arm of chromosome 7, at 7q11.23 (Ewart et al., 1993). Typically, individuals with WS have mild-to-moderate intellectual disabilities (ID), with IQ ranging from 40 to 90, and an average IQ in the low 60s (Howlin, Davies \& Udwin., 1998a; Tassabehji et al., 1999; Udwin \& Yule, 1991). Yet this low IQ belies the pattern of abilities in this syndrome. More accurately, the cognitive profile of WS consists of a complex, and often subtle, pattern of peaks and valleys, with verbal skills tending to be less impaired than visuo-spatial skills. Research into the nonverbal abilities of individuals with WS has often highlighted extensive deficits. For example, skills relating to number are often very poor, as are planning, problem solving and spatial cognition, including spatial working memory and visuo-spatial long-term memory (Ansari et al., 2003; Bellugi, Sabo \& Vaid, 1988; Bellugi et al., 2000; Farran \& Jarrold, 2003; Farran \& Jarrold, 2004; Vicari, Brizzolara \& Carlesimo, 2003; Vicari, Bellucci \& Carlesimo, 2005). In contrast to these deficits, face processing and some aspects of social cognition are seen as relative strengths (Karmiloff-Smith et al., 1995; Paul et al., 2002; Sullivan and Tager-Flusberg, 1999).

\section{Theories of visuo-spatial deficits}

Two main theories have been presented to explain the poor levels of performance shown by individuals with WS on visuo-spatial tasks. The first of these proposes that they have a local processing bias, i.e. they show a preference towards the processing of parts of an 
image at the expense of the overall global form (e.g. Bellugi et al., 1988; Bellugi et al., 1994). However, research has suggested that the level of processing at which individuals with WS focus may be related to the type of task in which they are engaged. For example, Pani, Mervis, and Robinson (1999) found that in a visual search task, in which participants must identify a target stimulus amongst distracter elements, adults with WS organised spatial arrays at a global level rather than local level. This pattern is comparable to TD adults. Furthermore, Farran, Jarrold and Gathercole (2003) demonstrated that a local processing bias presents itself at the level of production (e.g. when presented with tasks such as block construction) but not at the level of perception (e.g. when presented with identification versions of the Navon (1977) hierarchical processing task).

The second of the two theories highlights a potentially important difference in the functioning of the dorsal and ventral streams of the visual system. The dorsal stream is involved in the processing of spatial information, such as for location and motion, while the ventral stream is involved in the processing of information regarding faces and objects (Milner \& Goodale, 1995; Milner \& Goodale, 1996).

Behavioural research suggests that in WS, dorsal stream functions may be impaired relative to ventral stream functions (Atkinson et al., 1997; Atkinson et al., 2001; Eckert et al., 2005). Atkinson et al. (1997) found that in tasks such as form coherence and matching spatial orientation (which are associated with ventral stream functioning) children with WS performed at a similar level to TD controls, but on tasks such as global 
coherence of motion and visuomotor accuracy (which are associated with dorsal stream functioning) they performed worse than controls. Evidence of dorsal-ventral stream dissociation has also been identified in adults with WS (Atkinson et al., 2006; Paul et al., 2002).

Recent MRI and fMRI studies have investigated the cortical basis for the visuo-spatial deficits observed in WS. Schmitt et al. (2002) reported that, compared to chronological age (CA) matched TD controls, 17 individuals with WS showed reduced gyrification in the right parietal and right occipital lobes. This suggests some impairment in dorsal stream functioning. Meyer-Lindenberg et al. (2004) presented individuals with WS and IQ matched controls with a series of experiments such as object matching, pattern construction (a task which has some mental rotation requirements) and an attention to object or location task. While normal ventral stream activation was demonstrated, reduced activation was observed in the parietal lobe, which supports a relative impairment in the dorsal stream in WS (although note that chance performance was observed on the pattern construction task in WS). Consistent with other such studies (Eckert et al., 2005; Reiss et al., 2004), Meyer-Lindenberg et al. (2004) also found reduced volumes of grey matter in areas related to visuo-spatial processing, e.g. the occipitoparietal sulcus/vertical area of the intraparietal sulcus (see also MeyerLindenberg, Mervis \& Berman, 2006). This also supports a deficit in the dorsal stream. Interestingly, Meyer-Lindenberg suggest (2004) that not all dorsal stream functions would be affected by this reduction in grey matter, as some information (e.g. movement 
from pointlightwalker stimuli: see Jordan, Reiss \& Hoffman, 2002) can reach the dorsal stream without the need to pass through the parietal sulcus.

It is of note that dorsal stream deficits have been highlighted in other development disorders, such as dyslexia (Cornelissen et al., 1995) and autism (Spencer et al., 2000), indicating that this is not specific to WS and as such it is unlikely that impairment in dorsal stream functioning is wholly responsible for the unique pattern of visuo-spatial deficits observed in WS.

\section{Mental imagery: An alternate hypothesis}

According to Kosslyn (1995) "Imagery is a basic form of cognition, and plays a central role in many human activities - ranging from navigation to memory to creative problem solving" (p.1). In fact, these are some of the areas in which individuals with WS show particular difficulties. For example, Vicari et al. (1996) have demonstrated impairments in both short- and long-term visuo-spatial memory and in long-term verbal memory in WS. Navigational difficulties are also reported in children (Atkinson et al., 2001) and adults with WS (Farran, Blades, Tranter \& Boucher, 2006). It is plausible, therefore, that deficits observed in some areas of nonverbal ability in WS may arise as a result of a mental imagery deficit.

Kosslyn (1995) proposes that there are four kinds of mental imagery; generation, inspection, maintenance and transformation. As yet, in WS only mental transformation and image generation have been investigated. Farran, Jarrold and Gathercole (2001) 
examined mental image transformation using a rotation task. Participants were presented with two stick figures; "Sally", who held a red square in her left hand and a blue circle in her right hand, and "Jane", a mirror-reversal of Sally. On each trial participants were shown one of the two figures at one of six orientations $\left(0^{\circ}, 60^{\circ}, 120^{\circ}, 180^{\circ}, 240^{\circ}, 300^{\circ}\right)$ and were asked to indicate whether the figure was Sally or Jane. Two versions of the task were adopted, a manual rotation version (in which the stimuli were presented on a disc that could be physically rotated) and a mental rotation version (in which they had to imagine turning the figure in their mind). Farran et al. (2001) found that TD controls showed significantly stronger levels of performance overall than the WS group and, more importantly, that the WS participants were significantly worse on the mental rotation version than on the manual rotation version of the task. These results suggest that individuals with WS have difficulties with the 'mental' rotation aspect of the task.

Vicari, Bellucci and Carlisimo (2006) also report poor mental rotation ability in a group of individuals with WS, relative to TD controls matched for mental age (MA). Vicari et al. (2006) also investigated image generation in WS. The tasks were an adaptation of the Mental Colour Comparison Test (De Vreese, 1991) and the Animal tails task (Farah, Hammond, Levine \& Calvanio, 1988). In the former task, participants are asked whether the colours of two verbally presented objects are the same or different. In the latter task, participants are asked to judge which of two animals has the longest tail. On these tasks, the WS group performed at the same level as the TD controls. The authors suggest that the differentiation between performance on these tasks and the mental rotation tasks supports dissociation between ventral and dorsal stream processing in WS. 
It is possible that the deficit observed in mental rotation may reflect an overall impairment in image transformation in WS. Yet Farran and Jarrold (2004) found that the performance of WS participants on a mental size transformation task (in which participants were asked to indicate whether stimulus pairs were the same, regardless of any differences in size) was at a level comparable to TD non-verbal matched controls. It would appear then that the deficit observed in the mental rotation transformation task may occur as a result of a task specific feature. In addition, the differentiation between mental rotation and mental size transformation abilities in WS suggests that a dorsal stream deficit cannot explain all aspects of visuo-spatial cognition in WS.

\section{Mental rotation: Familiarity and stimulus component salience}

Recent research in both typical and atypical populations has begun to draw attention to important stimulus components that are involved in the process of mental rotation (Courbois, 1996, 2000, 2005). Two such elements are stimulus familiarity and stimulus component salience.

Courbois (1996) examined mental rotation abilities of TD children and individuals with ID (IQ range 40-63). Participants were presented with two mental rotation tasks that differed in the degree of familiarity of the stimulus. In the familiar version of the task a teddy bear was used as the stimulus, while in the unfamiliar version figures were taken from the Primary Mental Ability Space Test (Thurstone, 1958). Courbois (1996) found that for the familiar stimulus version of the task, the individuals with ID and the TD controls performed at a similar level. In contrast, when they were presented with 
unfamiliar stimuli the performance of the individuals with ID was reduced to the level of chance. This suggests that, in this population, performance on mental rotation tasks may be dependent upon the familiarity of the stimulus used.

It is unlikely, though not impossible, that familiarity would explain the poor performance by the individuals with WS in Farran et al's (2001) study. In order to make the decision as to whether the rotated stick figure was Sally or Jane the participants had to successfully identify them on three consecutive upright trials. This was facilitated by the differences between the two figures being explained. It was only once participants could discriminate between the stick figures (which one could argue involves familiarity) that the experiment began. In addition, Vicari, Bellucci and Carlesimo (2006) found that when individuals with WS were presented with a mental rotation task using letters (either an "L" or and "S" shape), presumably highly familiar figures, their performance was significantly worse than that of TD children matched for MA.

A second potentially important factor in mental rotation is the effect of salience, i.e. when one element of the stimulus is made more prominent than the remaining elements. Courbois (2000) presented children aged 5 and 8 years with pairs of unfamiliar shapes composed of four arms. Each of the shapes had a no salient component version and a salient version component. In the no salient component version all of the arms were of an approximately equal length, while in the salient component version one of the arms was nearly twice as long as the remaining three arms. Courbois (2000) found that the error rates were significantly higher in the no salient component condition than in the salient 
component condition and that this effect was far more dramatic in the 5-year-old group, whose performance in the no salient condition was often no better than chance. The same stimuli were employed in Experiment 1 of a subsequent study (Courbois, 2005). An effect of salience was present in children aged 7,9 and 11 years. This became smaller with increasing age.

An effect of stimulus salience has also been observed in young children. For example, Lourenco and Huttenlocher (2006) demonstrated that toddlers aged 18 to 25 months, could find a hidden object in a rotated space, when it was hidden at the unique corner of the triangular space, but performed at chance when it was hidden at one of the two equivalent corners. Similarly, Rosser, Ensing and Mazzeo (1985) report that 3-4-yearolds find it easier to rotate objects as a function of the number of orientation cues. It appears, then, that salient cues have an effect on mental rotation performance throughout typical development.

Courbois, Oross and Clerc (2007) also found a facilitatory effect of component salience for teenagers with ID (mean IQ: 54.5). This compared to a significant, but weaker effect in TD control groups matched for CA (mean CA: 16:6 years) and MA (mean CA: 8:0 years). The results of these studies have important implications for the present study. In younger children (around the age of 5 years), accuracy on mental rotation appears to be dependent upon the degree of salience of a stimulus. With development, children become increasingly capable of performing such tasks using stimuli that lack salient cues. Many studies indicate that the nonverbal abilities of individuals with WS are below the age of 8 
(e.g. Jarrold et al., 1998; Vicari et al., 2003). If poor performance on mental rotation tasks by this population arises as a result of developmental delay then, like the younger children, we would expect them to be able to carry out the task when the stimuli has a salient component but not when it lacks the salient cue. Another possibility is that performance on mental rotation may be limited by low IQ. Individuals with WS typically have mild-to-moderate ID with an average IQ around the midfifties/low sixties (Bellugi et al., 2000; Ewart et al., 1993; Howlin et al., 1998; Lenhoff, Perales \& Hickok, 2001). This is comparable to that of the ID group in both the Courbois (1996) and Courbois et al. (2007) studies. If individuals with WS show poor mental rotation ability as a result of their low IQ, it would be predicted that they should show a similar effect of axis salience to individuals with ID. If poor mental rotation ability in WS is a result of visuo-spatial processing style specific to WS, any effect of stimulus axis salience may show a different pattern to teenagers with ID and to the typical developmental trajectory, where an effect of stimulus saliency is consistently observed.

Research from studies involving individuals with ID and research from the developmental literature suggest that stimulus component salience plays an important role in mental rotation. The stimuli used by Farran et al. (2001) would certainly appear to have salient components in terms of the top (head), bottom (feet), left and right (arms) parts of the stimulus. Despite this, the individuals with WS made significantly more errors on the mental rotation task than the typically developing controls. Therefore, the aim of the present research is to provide clarification into the effect of stimulus component salience on mental rotation in WS. 


\section{Method}

\section{Participants}

Two groups of participants were compared in this study: Fifteen individuals with WS and 15 TD children. The WS group consisted of 10 males and five females (mean age = 22:09, s.d. $=9: 05$, range $=9: 02-38: 11)$, who were recruited through the Williams Syndrome Foundation (UK). All 15 of the WS participants had received a positive fluorescent in-situ hybridisation (FISH) test, confirming a microdeletion of the elastin gene on chromosome 7q11.23, which has found to be deleted in between $95 \%$ and $98 \%$ of individuals with WS (Lenhoff et al., 1997; Lowery, Morris, Ewart et al., 1995). The TD group consisted of eight males and seven females who were recruited from a mainstream primary school in Reading, Berkshire (mean age $=6: 04$, s.d. $=0$ :06, range $=$ 5:11 - 7:07). The two groups were matched individually for nonverbal ability using the Raven's Coloured Progressive Matrices (Raven, 1993). The mean scores of the groups on the Raven's Coloured Progressive Matrices were 19.8 (s.d. $=5.91$, range $=19-31$ ) for the WS group and 20 (s.d. $=5.87$, range $=19-31)$ for the TD group. Neither group had taken part in the studies on stimulus component salience by Coubois and his colleagues (Courbois, 2000; 2005; Courbois et al., 2007).

\section{Materials}

Three types of unfamiliar geometric shapes constructed of four arms were employed. Each had a no salient component version and a salient component version (see Figure 1). The structure of the two versions differed only in the dimension of the upper arm; for the no salient component version, each of the four arms were $2.5 \mathrm{~cm}$ long; for the salient component version, the lower, left and right arms were all $2.5 \mathrm{~cm}$ long and the upper arm 
$6 \mathrm{~cm}$ long. For the familiarisation phases the stimuli were presented as transparencies. For the experimental phase, the stimuli were presented on a computer monitor. The computer images were previously generated by one of the authors (YC) for use in the investigation of mental rotation in TD children (Courbois, 2000). For the present study, the same images were employed and the task was programmed in an experiment-generator software package (Superlab, 1999). This program randomised the order of presentation of the stimuli.

Figure 1 about here

\section{Design and Procedure}

The procedure consisted of three phases: upright stimuli familiarisation, rotated stimuli familiarisation, and experimental. Each participant was tested individually in one session lasting approximately 30 minutes in length. In the experimental phase, half of the participants were presented with the salient component condition first and half were presented with the no salient condition first. For all trials the participants were asked to give a verbal response of 'same' or 'different'. Fifty percent of trials were 'same' trials and $50 \%$ were 'different' trials (mirror imaged pairs of stimuli).

\section{Upright stimuli familiarisation}

In order to introduce the participants to the task and to establish that they were able to discriminate between same and different stimuli, an initial familiarisation phase was presented. For this participants were shown pairs of transparencies (half with no salient component and half with a salient component) with both of the upper arms upright (pointing to $0^{\circ}$ ), and were asked to indicate whether the two shapes were the same or 
different. After the participants had provided their responses the experimenter gave them visual feedback by placing the transparencies one on top of the other. In this way it was possible for them to see whether they were correct. Simultaneous verbal feedback was also given. The criterion for this phase was 3 correct responses in a row, with at least one 'same' and one 'different' trial type. All participants successfully completed this phase after a mean of 3 trials.

\section{Rotated stimulus familiarisation}

In order to introduce the participants to the rotation aspect of the task, the participants were once again presented with pairs of transparencies. In this phase the stimulus positioned on the left was presented with the upper arm upright while the stimulus positioned on the right was presented at one of 3 different orientations: $60^{\circ}, 120^{\circ}$, or $180^{\circ}$. Participants were then asked to indicate whether or not they thought the two shapes would be the same or different if the upper arms "were both pointing the same way". After each response, the stimulus on the right was manually rotated to the upright position and was placed on top of the model to enable the participants to tell whether they were correct. Verbal feedback was also provided. As before, the criterion for this phase was 3 correct responses in a row with at least one 'same' and one 'different' trial type. All participants successfully completed this phase after a mean of 6 trials.

\section{Experimental phase}

For each of the two experimental conditions (salient component and no salient component) participants were presented with six practice trials followed by 24 
randomised experiment trials ( 3 shapes* 4 angle of rotation* 2 stimulus type) on a computer screen. Stimuli for the trials were randomly selected from the experimental set by the computer. Three sets of shapes were employed. For each trial, the left-hand stimulus (the model) appeared upright throughout the experiment while the right-hand stimulus was rotated to one of four orientations $\left(0^{\circ}\right.$ : upright, $\left.60^{\circ}, 120^{\circ}, 180^{\circ}\right)$. The participants were asked to indicate through a verbal response whether the two objects on the screen were the same or different. In order to avoid any potentially confounding effects that may occur as a result of the fine motor difficulties that have been found to occur in WS (Wang et al., 1995), the participants' responses were immediately registered on the computer by the experimenter, who pressed either ' $S$ ' if the participant thought the stimuli would be the same or ' $\mathrm{D}$ ' if they thought they would be different. For all trials, both stimuli remained on screen until a correct response had been given. If an incorrect response was not corrected by the participants they were prompted by the experimenter.

\section{Results}

\section{Group matching}

Participants were matched individually according to their scores on the RCPM. An independent samples t-test, with RCPM score as the dependent variable and group as the independent variable (2 levels: WS, TD), indicated that there was no significant difference between the scores of the two groups on this measure of nonverbal ability, $t$ (28) $=-.09, p=.93$. A second independent samples t-test indicated that there was a significant difference between the chronological ages of the two groups, $\mathrm{t}(28)=-6.70, p$ $<.001(\mathrm{WS}>\mathrm{TD})$. 


\section{Analysis of correct responses}

Preliminary analysis indicated that the data set was normally distributed, $p>.05$. Number of correct responses were analysed by a mixed-factor ANOVA, with the within-subject factors of stimulus type ( 2 levels: salient component, no salient component) and angle of rotation (4 levels: $\left.0^{\circ}, 60^{\circ}, 120^{\circ}, 180^{\circ}\right)$, and the between-subject factor of group (2 levels: Williams syndrome, typically developing children). The mean numbers of correct responses by the two groups are shown in Table 1.

\section{Table 1 about here}

The main effect of group was significant, $F(1,28)=4.45, p<.05$ (partial $\eta^{2}=.14$ ). This was due to the TD group making significantly more correct responses than the WS group $(\mathrm{TD}$ mean $=4.36$, s.e. $=0.17$; WS mean $=3.89$, s.e. $=0.17)$. The main effect of stimulus type was significant, $F(1,28)=25.44, p<.001$ (partial $\eta^{2}=.48$ ), due to a significantly higher number of correct responses for the salient stimulus component condition (mean = 4.46 , s.e. $=0.12)$ than the no salient component condition $($ mean $=3.77$, s.e. $=0.15)$. There was a significant linear trend for angle of rotation, $F(1,28)=21.30, p<.001$, which indicates that the number of correct responses decreased linearly as the angle of rotation increased from $0^{\circ}$ through to $180^{\circ}$.

There were no significant two-way interactions: stimulus type by group, $p=.15$; angle of rotation by group, $p=.12$; stimulus type by angle of rotation, $p=.39$. There was a significant three-way interaction of stimulus type by angle of rotation by group, $F(3,84)$ $=5.20, p<.005$ (partial $\left.\eta^{2}=1.58\right)$. To examine this, separate ANOVAs were carried out 
for TD and WS groups. This indicated that there was no significant interaction between stimulus type and angle of rotation for the WS group, $F(3,42)=1.50, p=.23$ (partial $\eta^{2}$ $=.10$ ), but that the interaction between stimulus type and angle of rotation was significant for the TD group, $F(3,42)=4.93, p<.01\left(\right.$ partial $\left.\eta^{2}=.26\right)$. This was due to the TD controls showing a significant main effect of angle of rotation in the no salient component condition, $F(3,42)=11.76, p<.001$ (partial $\left.\eta^{2}=.46\right)$, but not in the salient component condition, $F(3,42)=1.01, p=.40\left(\right.$ partial $\left.\eta^{2}=.07\right)$.

Descriptive statistics suggest that the WS group may have been performing at around the level of chance (50\%: a score of 3 out of 6 ) on the majority of trials while the TD group were, generally, scoring above chance (see table 1). To examine this, one sample t-tests were carried out comparing the mean number of CRs to the test value of 3 (i.e. chance score). The analysis indicated that the scores of the WS group differed from that which could be expected by chance on only three of the trials. These were trials in the salient component condition at $0^{\circ}, t(14)=5.29, p<.001$, and $60^{\circ}, t(14)=6.00, p<.001$, and in the no salient component condition at $0^{\circ}, t(14)=5.10, p<.001$. On all other trials their performance was not significantly different from chance, $p>.05$. For the TD the mean number of CRs was significantly above chance on nearly all trials. In the salient component condition significantly higher scores were found at $0^{\circ}, t(14)=7.34, p<.001$, $60^{\circ}, t(14)=6.81, p<.001,120^{\circ}, t(14)=7.17, p<.001$ and $180^{\circ}, t(14)=4.36, p<.005$. While in the no salient component condition significantly higher scores were found at $0^{\circ}$, $t(14)=8.00, p<.001,60^{\circ}, t(14)=3.10, p<.01$ and $120^{\circ}, t(14)=2.29, p<.05$. The only 
trial at which the mean number of CRs made by the TD group did not differ significantly from chance was in the no salient condition at $180^{\circ}, p>.05$.

The results suggest that the significant effect of stimulus type observed for the WS in the initial repeated measure ANOVA may have been driven by their relatively good performance for trials at $0^{\circ}$. At this angle, mental rotation of the stimulus is not required to reach a conclusion as to whether or not the stimuli are the same. As such, to examine more closely as to whether there was an effect of stimulus component salience, the repeated measure ANOVA was rerun without the $0^{\circ}$ trials. The within-subject factors were stimulus type ( 2 levels: salient component, no salient component) and angle of rotation ( 3 levels: $\left.60^{\circ}, 120^{\circ}, 180^{\circ}\right)$, and the between-subject factor of group ( 2 levels: WS, TD children). The results indicated that there was a significant effect of stimulus type $F$ $(1,28)=23.51, p<.001\left(\right.$ partial $\left.\eta^{2}=.46\right)$, due to a significantly higher number of correct responses for the salient stimulus component condition (mean $=4.24$, s.e. $=0.16$ ) than the no salient component condition $($ mean $=3.46$, s.e. $=0.18)$. There was a significant linear trend for angle of rotation, $F(1,28)=8.49, \quad p<.01$, which indicates that the number of correct responses decreased linearly as the angle of rotation increased from $60^{\circ}$ through to $180^{\circ}$. The main effect of group was not significant, $p=.11$.

There was a significant stimulus type* group interaction $F(1,28)=5.71, p<.05$ (partial $\eta^{2}$ $=.17)$. This interaction was further investigated using t-tests. These analyses indicated that there was no significant difference between the groups in the no salient component condition $(t(28)=1.01, p=.32)$, but there was a significant difference in the salient 
component condition $(t(28)=2.83, p<.01)$, with the TD group making more correct respones than the WS group (TD: mean for no salient component $=3.51$, s.e. $=.26$, mean for salient component $=4.70$, s.e. $=.22 ; \mathrm{WS}$ : mean for salient component $=3.40$, s.e. $=$ .26 , mean for no salient component $=3.80$, s.e. $=.22$ ). This suggests that the performance of the TD group, but not the WS group, was improved by the salient component. There was a significant angle of rotation* group interaction, $F(1,28)=5.82, p<.05$ (partial $\eta^{2}=$ .17). This was due to a significant main effect of angle of rotation for the TD group, $F(2$, $28)=5.49, p=.01\left(\right.$ partial $\left.\eta^{2}=.28\right)$, but not for the WS group, $F(2,28)=3.12, p=.06$ (partial $\eta^{2}=.18$ ). There was no significant stimulus type*angle interaction, $p=.57$. There was a significant stimulus type*angle of rotation* group interaction, $F(1,56)=4.95$, $p<.05$ (partial $\eta^{2}=.15$ ). To examine this, separate ANOVAs were carried out for TD and WS groups. This indicated that the three-way interaction arose due to there being no significant interaction between stimulus type and angle of rotation for the WS group, $F$ $(2,28)=2.13, p=.14$ (partial $\left.\eta^{2}=.13\right)$, but that there was a significant quadratic trend between stimulus type and angle of rotation for the TD group, $F(1,14)=5.39, p<.05$ $\left(\right.$ partial $\left.\eta^{2}=.29\right)$.

Given the broad range of ages in the WS group it was necessary to examine whether there were any age related differences on performance. In order to examine any potential such correlation, Spearman's Rho was used. Spearman's Rho was used as alternative to the more usual Pearson's $r$ due to the small sample size. This indicated that there was no significant correlation between the age of the individuals with WS and their total scores on the trials in which the stimuli had no salient component (Spearman's rho $=.42, \mathrm{n}=15$, 
$p=.12$ ), their total scores on the trials in which the stimuli had a salient component (Spearman's rho $=.12, \mathrm{n}=15, p=.66$ ) and their total score for all types of trials combined (Spearman's rho $=.33, \mathrm{n}=15, p=.23$ ). This suggests that the pattern of performance of the WS group was independent of age. This is not an unusual finding in relation to research into visuo-spatial cognition in WS (e.g. Karmiloff-Smith et al., 2004; Thomas et al., 2001) as this area of cognition plateaus relatively early in development (e.g. Jarrold et al., 1998). In addition, investigation of the individual data for the WS group indicated that the performance by each participant was within 2 standard deviations of the mean for the salient component condition. This provides further support that the limited effect of salience may be taken as common to individuals with WS.

\section{Discussion}

This study investigated the effect of stimulus component salience on mental rotation ability in individuals with WS. Prior research indicated that a salient stimulus component can have an important role in facilitating performance on the mental rotation of unfamiliar objects. This has been shown to be the case throughout typical development (Courbois, 2000; Courbois 2005; Courbois et al., 2007; Lourenco \& Huttenlocher, 2006; Rosser et al., 1985) and also in individuals with mild-to-severe ID (Courbois, 2000; Courbois et al., 2007). While it may be the case that individuals with WS share cognitive characteristics with these two groups (with mean IQ scores comparable to the individuals with ID and nonverbal abilities at around the level of a typically developing 5- to 7-yearold), in the present investigation we found that stimulus salience did not generally facilitate the mental rotation abilities of individuals with WS. 
When presented with stimuli that did not contain a salient component, overall, individuals with WS performed at the level of chance. While they did perform above chance on the upright trials (which is informative in that it demonstrates that they were able to successfully discriminate between a shape and its mirror image), to do so does not require the ability to carry out mental rotation. Performance by the WS group was also above chance on trials presented at $60^{\circ}$ in the salient component condition. This suggests that under limited circumstances, i.e. when additional task demands such as the angular disparity between the two stimuli that are being compared is small, a salient stimulus component may facilitate mental rotation. However, this effect is substantially reduced compared to typical development. This is demonstrated by comparing the performance of the WS group in this study and the 5-year-old TD children in the Courbois (2000) study. In the no salient component condition, both groups scored at chance. Despite this similarity across groups, a crucial difference is observed in the salient cue condition, such that TD five-year-olds show a significant benefit, but that this does not appear to be the case for individuals with WS. It is unlikely that the WS pattern reflects an even lower developmental level, given that salience cues are beneficial at as young as 18-months (Lourenco \& Huttenlocher, 2006). Overall, stimulus component salience does not appear to be beneficial to individuals with WS, to the extent that is observed in typical development.

When taken in combination with the data from young TD children and individuals with ID, the absence of an effect of stimulus component salience on task performance by 
individuals with WS indicates that their impairment in carrying out mental rotation does not result from low IQ. Rather, it arises due to features specific to WS. The pattern of mental rotation performance in WS is discussed in relation to the two hypotheses discussed earlier, proposed to explain the unique profile of visuo-spatial cognition in WS. It has been suggested that individuals with WS process the local elements of an image at the expense of its global structure (e.g. Bihrle et al., 1989). While evidence from perceptual tasks refute this claim (e.g. Farran et al., 2003) evidence from production tasks such as the Block Design task of the Wechsler scales (e.g. Weschler, 1974, 1981) do highlight poor global organisation (Bellugi et al, 1988). Mental rotation could be argued to require some form of production, i.e. the generation and then manipulation of an internal representation of the figure to produce an upright version of the image. Therefore, it may be the case that the absence of an effect of a salient stimulus component arose as a result of the way in which the individuals with WS were processing the stimuli. In order to benefit from the salient axis it is necessary to take into account the way in which internal structure (the local level of the stimulus) affects the shape of the stimulus (the global level). Attending to the global configuration of the image, i.e. that the upper arm is longer than the other arms, provides a reference system that facilitates encoding of the stimulus. The impaired performance observed in the present study may have arisen because the individuals with WS were not attending to the global configuration and as such could not benefit from the salient component. Despite this, evidence suggests that mental rotation may not be a holistic task. Rather than figures being encoded and rotated as a global image it appears that it is a part of the stimulus that is identified and transformed (Dror et al., 1997; Just \& Carpenter, 1976). This suggests 
that a local bias in WS would not hinder performance on the task. However, the fact that the WS group did not benefit from the salient component (a local element) implies that even if they were processing locally the local part that they were attending to was not the salient part. This would suggest that poor mental rotation performance in WS does not relate to a local processing bias per se, but that the salience of each local part does not affect performance in WS as it does in typical development.

A second possible explanation for the observed deficits in mental rotation ability lies in dorsal stream functioning. In addition to the behavioural evidence presented by Atkinson et al. (1997), studies employing neuroimaging techniques have provided some support for impairment in dorsal stream functioning in WS. For example, recent MRI studies have identified reductions in posterior areas of the brain (notably the parietal and occipital lobes) of individuals with WS compared to individuals with Down syndrome (Jernigan et al., 1993) and typical adult controls (Reiss et al., 2000; Reiss et al., 2004). It is of note, however, that in a neuroanatomical analysis of the brain of four WS autopsy specimens, Galaburda and Bellugi (2000) found no evidence of a systematic bias affecting the architecture of dorsal stream areas.

In healthy adults, dorsal stream functioning has been demonstrated in mental rotation. Podzebenko et al. (2002) presented participants with a mental rotation task in which they had to identify whether alphanumeric characters were normal or mirror-reversals. During the task, fMRI was used to observe changes in the flow of blood in the brain. This revealed bilateral dorsal stream activation, particularly in the right parietal lobe. The 
finding of right parietal lobe activation is consistent with research examining mental rotation with PET (Harris et al., 2000) and ERPs (Milivojevic et al., 2003). Further, disruption of neural activity through repetitive transcranial magnetic stimulation (Harris \& Miniussi, 2003) and electrical stimulation (Zacks et al., 2003) has been found to interfere in task performance during mental rotation. While results such as this would suggest that impairment in dorsal stream functioning in WS could account for their deficit in mental rotation ability, it is unlikely be the sole contributor. Positron emission tomography scans of mental rotation and mental size transformation tasks have been highlighted similar patterns of activation within the dorsal areas of the brain (e.g. Larsen et al., 2000). While individuals with WS do perform poorly on mental rotation tasks their performance on a mental size transformation task is comparable to that of matched TD controls. This suggests that at most only some aspects of dorsal functioning may be impaired in WS.

Explanations for the deficit in mental rotation ability are not limited to these two theories. Recently, Farran and Jarrold (2004) have found evidence of impaired orientation discrimination in WS which could be responsible for the weak mental rotation performance that they reported previously (Farran et al., 2001; also see Farran, 2006). If this is the case, as both the salient component and no salient component conditions of the present study require orientation discrimination this could certainly explain why in the present study individuals with WS performed poorly overall. Atypical mental imagery abilities are likely to impact on many areas of visuo-spatial functioning. And thus, with 
further investigation, it will be possible to determine the extent to which this might explain the profile of visuo-spatial cognition in WS.

There are a number of future studies that could be employed in order to build upon the current understanding of mental rotation and other mental imagery abilities in WS. A more precise understanding of mental rotation in individuals WS may be achieved by further examining aspects of the stimuli that are being rotated, e.g. explicitly comparing whether performance is affected by the degree of familiarity of a stimulus or whether salience can be further increased to aid performance. In addition, direct comparisons between the performance of individuals with WS and controls with ID will strengthen the findings of the present research. As previously discussed, research examining mental transformation abilities in WS has produced mixed results. While the present study and that of Farran et al. (2001) have demonstrated that mental rotation presents individuals with WS with considerable difficulties, mental size transformation ability is comparable to TD controls (Farran \& Jarrold, 2004). This suggests that the image transformation ability per se is not impaired in WS. In order to further uncover the limits of this ability in individuals with WS it would be beneficial to investigate other types of image transformation such as mental subtraction and addition (Brandimonte et al., 1992a, 1992b) or mental paper-folding (Shepard \& Feng, 1972).

While these studies may provide important information into mental transformation abilities in individuals with WS this represents just a single component of mental imagery. Mental imagery consists of image generation, image inspection, image 
maintenance and image transformation (Kosslyn, 1995). While each of these types of imagery can be used in conjunction with one another, research has indicated that imagery as a whole is not unitary, but rather it consists of a set of distinct processes (Kosslyn et al., 1984; Kosslyn et al., 1990). By presenting individuals with WS with a battery of imagery task that include tests of image generation, maintenance and inspection (for examples of these see Kosslyn, 1980; Kosslyn et al., 1988) it will be possible to more fully understand the overall mental imagery capacities of this population which may, in turn, help to inform upon the underlying functions that are responsible for deficits observed in other areas in WS.

Weaknesses of the present study lie in the small sample size and the broad range of ages of the participants with WS. While this is often an inevitable consequence of research with individuals with rare disorders, it is important to acknowledge this limitation, in particular in reference to how well the results of the study can be generalised. Future replication of the study with a larger sample will help to clarify the extent to which the findings of the current research reflect the true pattern of performance for individuals with WS.

In conclusion, the present study has provided further evidence for a deficit in mental rotation ability in individuals with WS and has suggested that stimulus component salience does not appear to be beneficial to individuals with WS to the extent that is observed in typical development. 


\section{Author note}

We would like to thank the members of the Williams Syndrome Foundation (UK), who have kindly taken part in this study and the staff and pupils of Alfred Sutton Primary School for their assistance and co-operation. Correspondence concerning this article should be addressed to Chris Stinton, Institute of Psychiatry, Department of Psychology, Box 78, De Crespigny Park, London, SE5 8AF.

Electronic mail: christopher.stinton@iop.kcl.ac.uk 


\section{References}

Ansari, D., Donlan, C., Thomas, M. S. C., Ewing, S. A., Peen, T., \& Karmiloff-Smith, A. (2003). What makes counting count? Verbal and visuo-spatial contributions to typical and atypical number development. Journal of Experimental Child Psychology, 85, 50-62.

Atkinson, J., King, J., Braddick, O., Noakes, L., Anker, S., \& Braddick, F. (1997). A specific deficit of dorsal stream function in Williams syndrome. Neuroreport: An International Journal for the Rapid Communication of Research in Neuroscience, 8, 1912-1922.

Atkinson, J., Anker, S., Braddick, O., Nokes, L., Mason, A., \& Braddick, F. (2001). Visual and Visuospatial development in young children with Williams syndrome. Developmental Medicine and Child Neurology, 43, 330-337.

Atkinson, J., Braddick, O., Rose, F. E,. Searcy, Y.M,. Wattam-Bell, J., \& Bellugi, U. (2006). Dorsal-stream motion processing deficits persist into adulthood in Williams syndrome. Neuropsychologia, 44, 828-833.

Bellugi, U., Lichtenberger, L., Jones, W., Lai, Z., \& St. George. (2000). The neurocognitive profile of Williams syndrome: a complex pattern of strengths and weaknesses. Journal of Cognitive Neuroscience, 12, 7-29.

Bellugi, U., Sabo, H., \& Vaid, J. (1988). Spatial deficits in children with Williams syndrome. In J. Stiles-Davis, M. Kritchevsky \& U Bellugi (Eds.), Spatial cognition: brain bases and development, Hillside, New Jersey: Lawrence Erlbaum Associates. 
Bellugi, U., Wang, P. P,. \& Jernigan, T. L. (1994). Spatial deficits in children with Williams syndrome: An unusual neuropsychological profile. In S.H. Broman \& J. Grafman (Eds.), Atypical cognitive deficits in developmental disorders: Implications for brain function (pp. 23-56). Hillsdale, N.J.: Lawrence Erlbaum Associates.

Cornelissen, P., Richardson, A., Mason, A., Fowler, S., \& Stein. J. (1995). Contrast sensitivity and coherent motion detection measured at photopic luminance levels in dyslexics and controls. Vision Reseach, 35, 1483-1494.

Courbois, Y. (1996). Evidence for visual imagery deficits in persons with mental retardation. American Journal on Mental Retardation, 101, 130-148.

Courbois, Y. (2000). The role of stimulus axis salience in children's ability to mentally rotate unfamiliar figures. European Journal of Cognitive Psychology, 12, 261269.

Courbois, Y. (2005). The development of mental rotation: effect of stimulus axis salience and its alignment with the vertical direction. Annee Psychologique, 105, 269-386.

Courbois, Y., Oross, S., \& Clerc, J. (2007). Mental rotation of unfamiliar stimuli in teenagers with mental retardation: the role of feature salience. American Journal on Mental Retardation, 112, 311 - 318.

DeVreese L. P. (1991) Two systems for colour-naming defects: Verbal disconnection vs. colour imagery disorder. Neuropsychologia 29, 1-18.

Eckert, M. A., Hu, D., Eliez, S., Bellugi, U., Galaburda, A., Korenberg. J., Mills, D., \& Reiss, A. L. (2003). Evidence for superior parietal impairment in Williams syndrome. Neurology, 64, 152-153. 
Ewart, A. K., Morris, C. A., Atkinson, D., Jin, W., Sternes, K., Spallone, P., Stock, A. D., Leppert, M., \& Keating, M. T. (1993). Hemizygosity at the elastin locus in developmental disorder: williams syndrome. Nature Genetics, 5, 11-16.

Farah M. J., Hammond K. M., Levine D. N., Calvanio R. (1988) Visual and spatial mental imagery: Dissociable systems of representation. Cognitive Psychologl 20, 439-462.

Farran, E. K. (2006). Orientation coding: A specific deficit in Williams syndrome? Developmental Neuropsychology, 29, 397-414.

Farran. E. K., Blades, M., Tranter, L., Boucher, J..(2006, September) How do individuals with Williams syndrome learn a route? Paper presented at the British Psychological Society Developmental Section Annual Conference, Edinburgh, UK.

Farran, E. K., \& Jarrold, C. (2003). Visuo-spatial cognition inWilliams syndrome: Reviewing and accounting for the strengths and weaknesses in performance. Developmental Neuropsychology, 23, 175-202.

Farran, E. K., \& Jarrold, C. (2004). Exploring block construction and mental imagery: evidence of atypical orientation discrimination in Williams syndrome. Neuropsychologia, 11, 1019-1039.

Farran, E. K., Jarrold, C., \& Gathercole, S. E. (2001). Block design performance in the Williams syndrome phenotype: a problem with mental imagery. Journal of Child Psychology and Psychiatry, 42, 719-728. 
Farran, E. K., Jarrold, C., \& Gathercole, S. E. (2003). Divided attention, selective attention and drawing: processing preferences in Williams syndrome are dependent on the task administered. Neuropsychologia, 41, 676-687.

Grant, J., Valian, V., \& Karmiloff-Smith, A. (2002). A study of relative clauses in Williams syndrome. Journal of Child Language, 29, 403-416.

Howlin, P., Davies, M., \& Udwin, O. (1998). Cognitive functioning in adults with Williams syndrome. Journal of Child Psychology and Psychiatry, 39, 183-189.

Jarrold, C,. Baddeley, A. D., \& Hewes, A. K. (1998) Verbal and nonverbal abilities in the Williams syndrome phenotype: evidence for diverging developmental trajectories. Journal of Child Psychology and Psychiatry, 39, 511-523.

Jordan, H., Reiss, J., Hoffman, J. E., \& Landau, B. (2002). Intact perception of biological motion in the face of profound spatial deficits: Williams syndrome. Psychological Science, 13, 162-167.

Kosslyn, S. M. (1995). Imagery and brain: the resolution of the imagery debate. Cambridge, MA: MIT Press.

Karmiloff-Smith, A. (1998). Development itself is the key to understanding developmental disorders. Trends in Cognitive Sciences, 2, 389-398.

Karmiloff-Smith, A., Klima, E., Bellugi, U., Grant, J., \& Baroncohen, S. (1995). Is there a social module - Language, face processing, and theory of mind in individuals with Williams-syndrome. Journal of Cognitive Neuroscience, 7, 196-208.

Karmiloff-Smith, A., Thomas, M., Annaz, D., Humphreys, K., Ewing, S., Brace, N. et al. (2004). Exploring the Williams syndrome face-processing debate: the importance 
of building developmental trajectories. Journal of Child Psychology and Psychiatry, 45, 1258-1274.

Lenhoff, H. M., Perales, O., \& Hickok. G. (2001). Absolute pitch in Williams syndrome. Music Perception, 18, 491-503.

Lenhoff, H. M., Wang, P. P., Greenberg, F., \& Bellugi, U. (1997). Williams syndrome and the brain. Scientific American, 277, 42-47.

Lourenco, S. F., \& Huttenlocher, J. (2006). How do young children determine location? Evidence from disorientation tasks. Cognition, 100, 511-529.

Lowery, M. C., Morris, C. A., Ewart, A. K., Brothman, L. J., Zhu, X. L., Leonard, C. O., Cary, J. C., Keatin, M., \& Brothman, A. R. (1995). Strong correlation of elastin deletions, detected by FISH, with Williams syndrome: evaluation of 235 patients. American Journal of Human Genetics, 57, 49-53.

Meyer-Lindenberg, A., Kohn, P., Mervis, C. B., Kippenham, J. S., Olsen, R. K., Morris, C. A., \& Berman, K. F. (2004). Neural basis of genetically determined visuospatial construction deficit in Williams syndrome. Neuron, 43, 623-631.

Meyer-Lindeberg, A., Mervis, C.B., \& Berman, K.F. (2006). Neural mechanisms in Williams syndrome: A unique window to genetic influences on cognition and behaviour. Nature, 7, 380-393.

Milner, A. D. \& Goodale, M. A. (1995). The Visual Brain in Action. Oxford University Press, Oxford.

Milner, A.D. \& Goodale, M. A. (1996). The objects of action and perception. Cognition, 67, 181-207. 
Morris, C. \& Mervis, C. (1999). Williams syndrome. In Goldstein, S. \& Reynolds, C.R. (Eds.) Handbook of neurodevelopmental and genetic disorders in children. New York, NY: Guilford Press.

Murray, J. E. (1997). Flipping and spinning: Spatial transformation procedures in the identification of rotated natural objects. Memory and Cognition, 25, 96-105.

Navon, D. (1977). Forest before trees: the precedence of global features in visual perception. Cognitive Psychology, 9, 353-385.

Pani, J. R., Mervis, C. B., \& Robinson, B. F. (1999). Global spatial organisation by individuals with Williams syndrome. Psychological Science, 10, 453-458.

Paul, B. M., Stiles, J., Passarotti, A., Bavar, N., \& Beullgi, U. (2002). Face and place processing in Williams syndrome: evidence for a dorsal-ventral dissociation. Cognitive Neuroscience and Neuropsychology, 13, 1115-1119.

Phillips, C. E., Jarrold, C., Baddeley, A. D., Grant, J., \& Karmiloff-Smith, A. (2004). Comprehension of spatial language terms in Williams syndrome: Evidence for an interaction between domains of strength and weakness. Cortex, 40, 85-101.

Plissart, L. \& Fryns, J. P. (1999). Early development (5 to 48 months) in Williams syndrome. A study of 14 children. Genetic Counseling, 10, 151-156.

Raven, J. C. (1993). Coloured progressive matrices. Oxford: Information Press.

Reilly, J. S., Klima, E., \& Bellugi, U. (1991). Once more with feeling: Affect and language in atypical populations. Developmental Psychopathology, 2, 367-391.

Reiss, A. L., Eckert, M. A., Rose, F. E., Karchemskiy, A., Kesler, S., Chang, M., Reynolds, M. F., Kwon, H., \& Galaburda, A. (2004). An experiment of nature: 
Brain anatomy parallels cognition and behaviour in Williams syndrome. Journal of Neuroscience, 24, 5009-5015.

Rosser, R. A., Ensing, S., \& Mazzeo, J. (1985). The role of stimulus salience in young children's ability to discriminate two-dimensional rotations: Reflections on a paradigm. Contemporary Educational Psychology, 10, 95-103.

Schmitt, J. E., Eliez, S., Bellugi, U., Galaburda, A., \& Reiss, A. L. (2002). Increased gyrification in Williams syndrome: evidence using 3D MRI methods. Developmental Medicing and Child Neurology, 44, 292-295.

Singer-Harris, N., Bellugi, U., Bates, E., Jones, W., \& Rossen, M. (1997). Contrasting profiles of language development in children with Williams and Down syndromes. Developmental Neuropsychology, 13: 345-70.

Spencer, J., O’Brien, J., Riggs, K., Braddick, O., Atkinson, J., \& Wattam-Bell, J. (2000). Motion processing in autism: evidence for a dorsal stream deficiency. Neuroreport: For Rapid Communication of Neuroscience Research, 11, 27652767.

Sullivan, K. \& Tager-Flusberg, H. (1999). Second-order belief attribution in Williams syndrome: Intact or impaired? American Journal on Mental Retardation, 104, 523-532.

SuperLab. (1999). SuperLab. Phoenix: Cedrus Corporation.

Tassabehji, M., Metcalfe, K., Karmiloff-Smith, A., Carette, M. J., Grant, J., Dennis, N., Reardon, W., Splitt, M., Read, A. P., \& Donnai, D. (1999). Williams syndrome: Use of chromosomal microdeletions as a tool to dissect cognitive and physical phenotypes. American Journal of Human Genetics, 64, 118-125. 
Thurstone, T. G. (1958). Manual for the SRA primary mental abilities. Chicago: Science Research Associates.

Udwin, O., Davies, M., \& Howlin, P. (1996). A longitudinal study of cognitive abilities and educational attainment in Williams syndrome. Developmental Medicine and Child Neurology, 38, 1020-1029.

Udwin, O. \& Yule, W. (1991). A cognitive and behavioral-phenotype in Williams syndrome. Journal of Clinical and Experimental Neuropsychology, 13, 232-244.

Vicari, S., Bellucci, S., \& Carlesimo, G.A. (2003). Visual and spatial working memory: evidence from Williams syndrome. Developmental Medicine and Child Neurology, 45, 269-273.

Vicari, S., Bellucci, S., \& Carlesimo, G. (2005). Visual and spatial long-term memory: Differential pattern of impairments in Williams and Down syndromes. Developmental Medicine and Child Neurology, 47, 305-311.

Vicari, S., Bellucci, S., \& Carlesimo, G. A. (2006). Evidence from two genetic syndromes for the independence of spatial and visual working memory Developmental Medicine and Child Neurology, 48, 126-131.

Vicari, S., Brizzolara, D., Carlesimo, G. A., Pezzini, G., \& Volterra, V. (1996). Memory abilities in children with Williams syndrome. Cortex, 32, 503-514.

Wang, P. P., Doherty, S., Rourke, S. B., \& Bellugi, U. (1995). Unique profile of visuoperceptual skills in a genetic syndrome. Brain and Cognition, 29, 54-65. 
Table 1. Mean number of correct responses

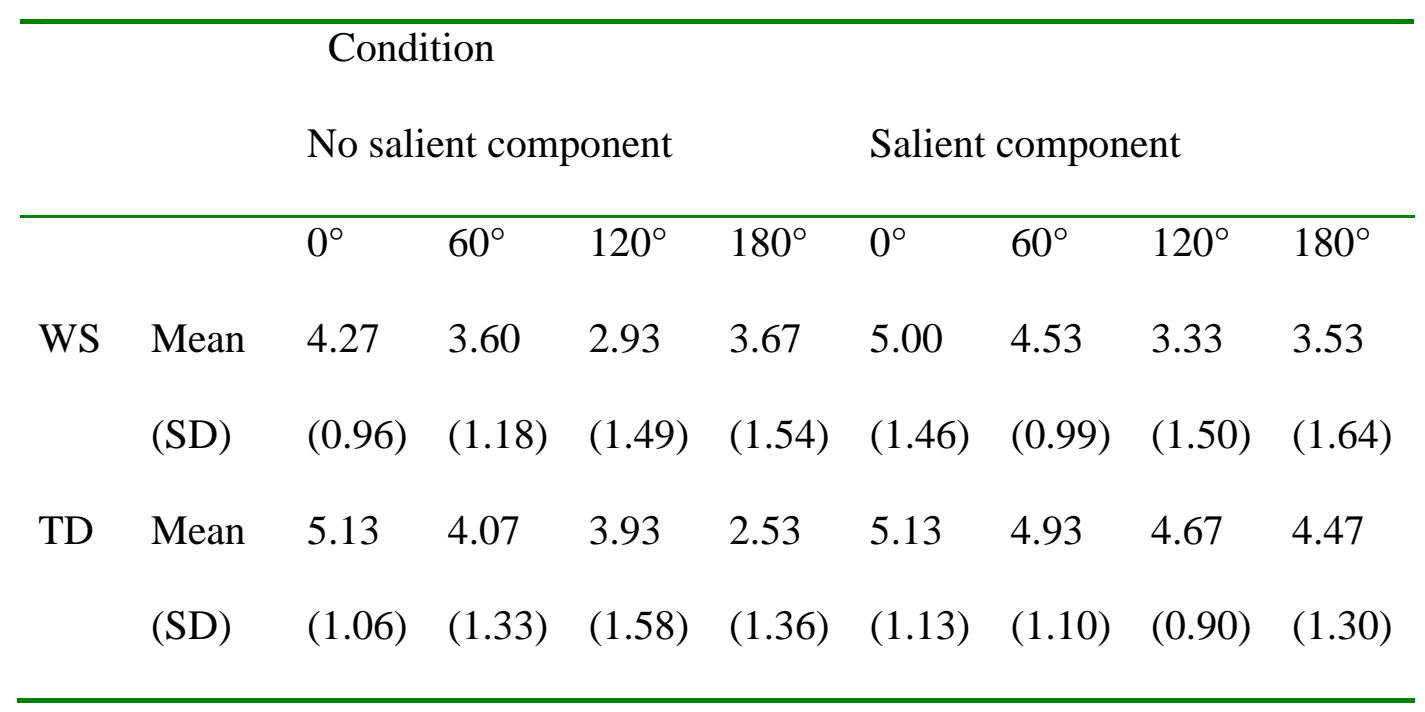


Figure 1: Examples of stimuli (top: no salient component 'same' trial; bottom: salient component 'different' trials)
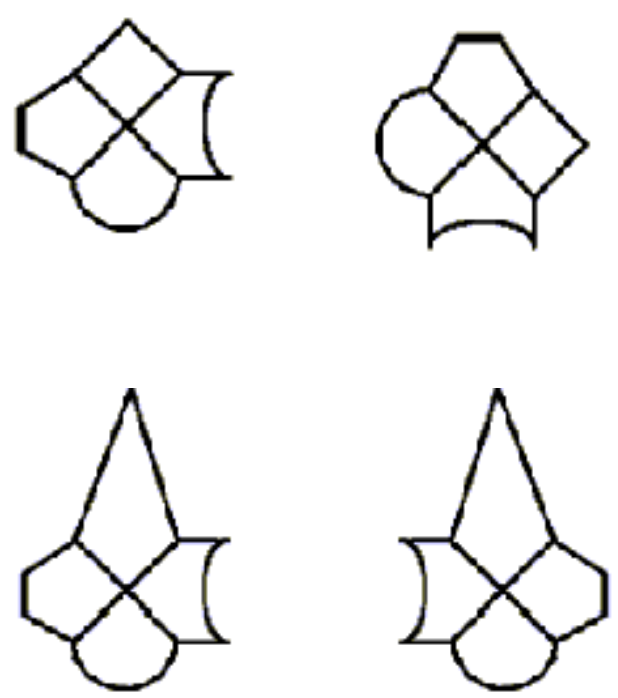